\title{
Microbial conversion of inorganic carbon to dimethyl sulfide in anoxic lake sediment (Plußsee, Germany)
}

\author{
Y. S. Lin ${ }^{1}$, V. B. Heuer ${ }^{1}$, T. G. Ferdelman ${ }^{2}$, and K.-U. Hinrichs ${ }^{1}$ \\ ${ }^{1}$ Organic Geochemistry Group, Department of Geosciences and MARUM Center for Marine Environmental Sciences, \\ University of Bremen, P.O. Box 330 440, 28334 Bremen, Germany \\ ${ }^{2}$ Max-Planck-Institute for Marine Microbiology, Celsiusstr. 1, 28359 Bremen, Germany
}

Received: 30 March 2010 - Published in Biogeosciences Discuss.: 8 April 2010

Revised: 9 July 2010 - Accepted: 3 August 2010 - Published: 16 August 2010

\begin{abstract}
In anoxic environments, volatile methylated sulfides like methanethiol (MT) and dimethyl sulfide (DMS) link the pools of inorganic and organic carbon with the sulfur cycle. However, direct formation of methylated sulfides from reduction of dissolved inorganic carbon has previously not been demonstrated. When studying the effect of temperature on hydrogenotrophic microbial activity, we observed formation of DMS in anoxic sediment of Lake Plußsee at $55^{\circ} \mathrm{C}$. Subsequent experiments strongly suggested that the formation of DMS involves fixation of bicarbonate via a reductive pathway in analogy to methanogenesis and engages methylation of MT. DMS formation was enhanced by addition of bicarbonate and further increased when both bicarbonate and $\mathrm{H}_{2}$ were supplemented. Inhibition of DMS formation by 2-bromoethanesulfonate points to the involvement of methanogens. Compared to the accumulation of DMS, MT showed the opposite trend but there was no apparent 1:1 stoichiometric ratio between both compounds. Both DMS and MT had negative $\delta^{13} \mathrm{C}$ values of $-62 \%$ and $-55 \%$, respectively. Labeling with $\mathrm{NaH}^{13} \mathrm{CO}_{3}$ showed more rapid incorporation of bicarbonate into DMS than into MT. The stable carbon isotopic evidence implies that bicarbonate was fixed via a reductive pathway of methanogenesis, and the generated methyl coenzyme $\mathrm{M}$ became the methyl donor for MT methylation. Neither DMS nor MT accumulation were stimulated by addition of the methyl-group donors methanol and syringic acid or by the methyl-group acceptor hydrogen sulphide. The source of MT was further investigated in a $\mathrm{H}_{2}^{35} \mathrm{~S}$ labeling experiment, which demonstrated a microbially-mediated process of hydrogen sulfide methy-
\end{abstract}

Correspondence to: Y. S. Lin (yushih@uni-bremen.de) lation to MT that accounted for only $<10 \%$ of the accumulation rates of DMS. Therefore, the major source of the ${ }^{13} \mathrm{C}$-depleted MT was neither bicarbonate nor methoxylated aromatic compounds. Other possibilities for isotopically depleted MT, such as other organic precursors like methionine, are discussed. This DMS-forming pathway may be relevant for anoxic environments such as hydrothermally influenced sediments and fluids and sulfate-methane transition zones in marine sediments.

\section{Introduction}

Among volatile organic sulfur compounds, the methylated sulfides - dimethyl sulfide (DMS) and, to a lesser extent, methanethiol (MT, or methyl mercaptan) - are the most abundant components. The biogeochemical processes involving methylated sulfides in ocean surface waters have received particular attention because of the connection between DMS and climate (Charlson et al., 1987). In anoxic environments, DMS and MT link carbon and sulfur cycles in diverse ways. In contrast to complex organic sulfur compounds formed during early diagenesis that are refractory to biodegradation (Ferdelman et al., 1991), DMS and MT remain reactive and available for microbial processes. Their role as intermediates during remineralization of organic matter has been elaborated in earlier studies and is briefly summarized below and in Fig. 1. Decomposition of S-methyl compounds (compounds with methyl groups bonding to a sulfur atom) such as dimethylsulfoniopropionate (DMSP) and methionine initially yields DMS or MT (Kiene et al., 1990), both of which can be further catabolized by microbes that respire anaerobically. Isolated microorganisms that are

Published by Copernicus Publications on behalf of the European Geosciences Union. 


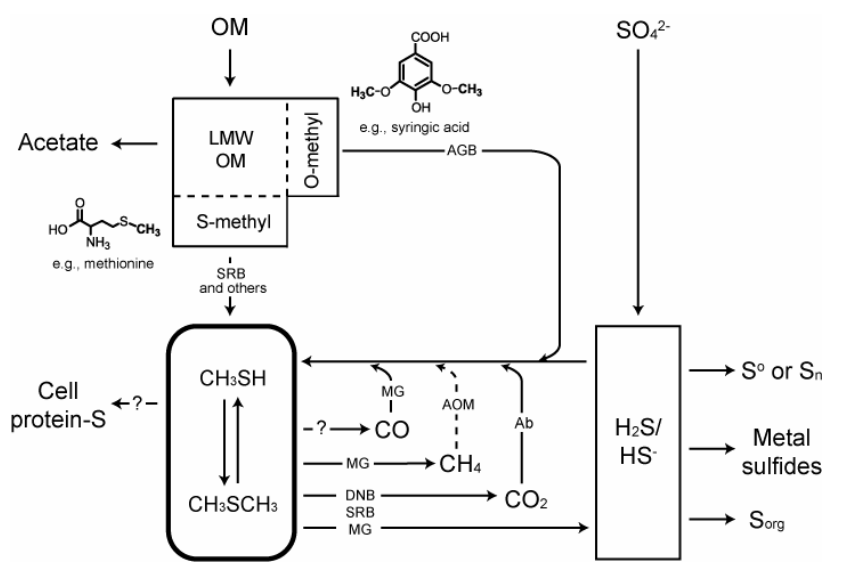

Fig. 1. A schematic diagram summarizing geochemical processes linked by methylated sulfides in anoxic environments. Arrows with dashed line: hypothesized processes; arrows with a question mark: processes that have not been examined. See text for detailed discussion. The structures of syringic acid and methionine are also shown as examples of compounds with O- and S-methyl groups, respectively. Abbreviations: Ab, abiotic process; AGB, acetogenic bacteria; AOM, anaerobic oxidation of methane; DNB, denitrifying bacteria; LMW, low molecular weight; MG, methanogens; OM, organic matter; $S_{\text {org }}$ : sulfurized OM formed during early diagenesis; $\mathrm{SRB}$, sulfate reducing bacteria.

known to oxidize methylated sulfides include denitrifying bacteria (Visscher and Taylor, 1993), sulfate reducing bacteria (Tanimoto and Bak, 1994) and methanogens (Lomans et al., 1999a). During degradation of DMS, MT usually accumulates transiently as an intermediate (Lomans et al., 1999b). Whether methylated sulfides can be used to synthesize protein-sulfur during anabolism in anoxic environments is not clear, but evidence exists that pelagic marine bacterioplankton preferentially assimilate methylated sulfides over sulfate or hydrogen sulfide (Kiene et al., 1999).

In addition to processes whereby methylated sulfides are produced from organic sulfur compounds, other processes exist in which methylated sulfides are derived by linking organic or inorganic carbon to $\mathrm{H}_{2} \mathrm{~S} / \mathrm{HS}^{-}$(hydrogen sulfide hereafter), either biologically and/or abiotically (Fig. 1). First, O-methyl groups (methyl groups bonding to an oxygen atom) can be transferred microbially to hydrogen sulfide to form MT, with additional methylation under certain circumstances yielding DMS (Lomans et al., 2002). Known O-methyl donors include methanol (van Leerdam et al., 2006) and methoxylated aromatic compounds such as lignin monomers (Lomans et al., 2002). This process is proposed to be the main mechanism contributing to methylated sulfides in DMSP-limited freshwater sediments, as evidenced by the strong correlation between concentrations of methylated sulfides and hydrogen sulfide in lake sediment (Lomans et al., 1997). Second, based on the study of trace methane oxidation of Methanosarcina acetivorans, Moran et al. (2007) hypothesized that during anaerobic oxidation of methane (AOM), methane is converted to methylated sulfides, which are subsequently oxidized by sulfate reducers. It is currently not known whether and exactly how such coupling proceeds in AOM organisms. Third, conversion of carbon monoxide (CO) to MT and DMS has also been observed in M. acetivorans (Moran et al., 2008), which represents the first finding of microbially mediated incorporation of inorganic carbon into methylated sulfides. The process probably proceeds via stepwise reduction of $\mathrm{CO}$ as coenzyme-bound intermediates to form a methyl group and could be coupled to energy conservation via a chemiosmotic mechanism. However, this process has not yet been studied using environmental samples, and the lack of knowledge on $\mathrm{CO}$ abundance in aquatic environments hampers evaluation of the significance of this process in natural settings. Last, small alkyl$\mathrm{S}$ molecules, except DMS, can be abiotically synthesized from carbon dioxide $\left(\mathrm{CO}_{2}\right)$ and hydrogen sulfide in the presence of iron monosulfide under anoxic conditions (Heinen and Lauwers, 1996). This process is accelerated at temperatures higher than $50^{\circ} \mathrm{C}$. The abiotically synthesized alkylated sulfides are considered as building blocks for larger organic molecules in the primitive earth (Huber and Wächtershäuser, 1997). Jointly, these biological and abiotic reactions compete for hydrogen sulfide with other reactions such as the formation of elemental sulfur, polysulfur, metal sulfides and complex organic sulfur compounds.

The finding of formation of methyl sulfides from $\mathrm{CO}$ by $M$. acetivorans raises the question whether $\mathrm{CO}_{2}$ (or bicarbonate at neutral $\mathrm{pH}$ ), the most abundant dissolved inorganic carbon species in natural waters, can be converted to MT and DMS by microbial activity. Although $\mathrm{CO}_{2}$ is not a growth substrate of $M$. acetivorans, it is produced in vivo via oxidation of $\mathrm{CO}$ and then introduced into the reductive steps by methanofuran (Oelgeschläger and Rother, 2008), a coenzyme shared by autotrophic methanogens. In anoxic environments, reduction of $\mathrm{CO}_{2}$ to a methyl group is mostly coupled to hydrogenotrophy, such as autotrophic methanogenesis and acetogenesis. Previous studies of the effect of molecular hydrogen $\left(\mathrm{H}_{2}\right)$ on methylated sulfides have yielded inconclusive results. Lomans et al. (1999b) found that after prolonged incubation of anoxic lake sediment under $\mathrm{H}_{2}$, degradation of methylated sulfides decreased dramatically. In contrast, the addition of $\mathrm{H}_{2}$ did not affect thiol methylation potential in wetland sediments (Stets et al., 2004).

In an experiment in which we studied hydrogenotrophic reactions as a function of temperature in the anoxic sediment of the eutrophic Lake Plußsee, we detected DMS production after addition of $\mathrm{H}_{2}$ and bicarbonate at $55^{\circ} \mathrm{C}$. This observation points to the potential presence of a hitherto unrecognized pathway of DMS formation that may be relevant to certain ecosystems functioning at higher temperatures. Our study tested whether this reaction is in fact mediated biologically and further examined the link among $\mathrm{CO}_{2}, \mathrm{H}_{2}$, hydrogen sulfide, and methylated sulfides. We performed 
experiments to characterize the mechanism and to identify the microbial group responsible for the production of methylated sulfides in sediment slurry incubations. The effect of $\mathrm{H}_{2}$ and bicarbonate on methylated sulfides, methane and acetate was examined, followed by tests aimed at verifying whether the observed DMS formation is related to methyl transfer during O-demethylation from organic substrates. We used a specific inhibitor to investigate the involved enzymatic pathway, which was subsequently supported by a study of the natural carbon isotopic abundance in methylated sulfides. The flow of C-and S-atoms into MT and DMS was further tracked by isotope labeling using ${ }^{13} \mathrm{C}$ - and ${ }^{35} \mathrm{~S}$-labeled compounds.

\section{Materials and methods}

\subsection{Study site and sampling}

Lake Plußsee $\left(54^{\circ} 10^{\prime} \mathrm{N}, 10^{\circ} 23^{\prime} \mathrm{E}\right)$ is a well-studied eutrophic lake located in northern Germany. It has a stable thermal stratification in summer and regularly occurring anoxia in the hypolimnion, leading to high hydrogen sulfide concentrations in the bottom water (up to $50 \mu \mathrm{mol} \mathrm{L}^{-1}$; Eller et al., 2005). Sediment samples used for this study were collected in July 2006 from the deepest part of the lake, i.e., at $28 \mathrm{~m}$ using a small multicorer from a rowboat. After sampling, the upper $15-\mathrm{cm}$ portion of triplicate sediment cores was transferred into an air-tight bottle without gas headspace and stored in the dark at $4{ }^{\circ} \mathrm{C}$ for three months before being used for incubation experiments.

\subsection{Slurry preparation}

Sediment slurries were prepared anoxically by homogenizing approximately one volume of sediment with one volume of sterilized distilled water. After autoclaving, the distilled water was sparged with nitrogen $\left(\mathrm{N}_{2}\right)$ for at least one hour to remove dissolved oxygen. $\mathrm{NaHCO}_{3}$ was added as buffer after sparging (final concentration $=1$ to $3 \mathrm{mmol} \mathrm{L}-1$ ) and $\mathrm{Na}_{2} \mathrm{~S} \cdot 9 \mathrm{H}_{2} \mathrm{O}$ as reducing agent (final concentration $=50 \mu \mathrm{mol} \mathrm{L}^{-1}$ ). Aliquots of 8 or $10 \mathrm{~mL}$ of sediment slurry were dispensed into $16 \mathrm{~mL}$ Hungate tubes and sealed with butyl rubber stoppers. The tubes were evacuated three times and flushed with $\mathrm{N}_{2}$ or $\mathrm{H}_{2}$, and were finally pressurized to $200 \mathrm{kPa}$. All the tubes were incubated at $55^{\circ} \mathrm{C}$ in the dark without shaking.

\subsection{Substrate and inhibitor amendments}

Substrate and inhibitor concentrations are reported for a liquid phase that is ca. $95 \%(\mathrm{w} / \mathrm{w})$ of the sediment slurry. $\mathrm{NaHCO}_{3}$ was added to $10 \mathrm{mmol} \mathrm{L}^{-1}$ from a $\mathrm{CO}_{2}$-stabilized stock solution. Other tested substrates (reported in final concentrations) include: $\mathrm{Na}_{2} \mathrm{~S} \cdot 9 \mathrm{H}_{2} \mathrm{O}$, $200 \mu \mathrm{mol} \mathrm{L}^{-1} \mathrm{MT}$, $50 \mu \mathrm{mol} \mathrm{L}^{-1}$, methanol, $800 \mu \mathrm{mol} \mathrm{L}^{-1}$; syringic acid, $100 \mu \mathrm{mol} \mathrm{L}^{-1}$. 2-Bromoethanesulfonic acid (BES, $20 \mathrm{mmol} \mathrm{L}^{-1}$ ) was applied to inhibit methanogenesis.

\subsection{Stable isotope labeling}

$\mathrm{NaH}^{13} \mathrm{CO}_{3}$ was spiked in the middle of an experiment, which was initiated by addition of both $\mathrm{H}_{2}$ and $10 \mathrm{mmol} \mathrm{L}^{-1}$ $\mathrm{NaHCO}_{3}$ at time zero. Assuming that the consumption kinetics of bicarbonate was identical to that of the parallel incubations with substrate amendments, we added $80 \mu \mathrm{mol} \mathrm{L}^{-1}$ $\mathrm{NaH}^{13} \mathrm{CO}_{3}\left(99.9 \%{ }^{13} \mathrm{C}\right)$ to achieve a final ${ }^{13} \mathrm{C}$ abundance of $\sim 2 \%$ of the estimated bicarbonate concentration remaining at this time point $\left(\sim 4 \mathrm{mmol} \mathrm{L}^{-1}\right)$. The exact ${ }^{13} \mathrm{C}$ content of the spiked $\mathrm{NaHCO}_{3}$ pool was not confirmed by stable carbon isotope analysis.

Before stable carbon isotopic analysis of DMS and MT, Hungate tubes were stored after incubation for one month at $-20^{\circ} \mathrm{C}$. To improve the transfer of DMS and MT vapors into the headspace, the tubes were heated to $60^{\circ} \mathrm{C}$ for $20 \mathrm{~min}$ prior to analysis.

\subsection{Radioisotope labeling}

In the labeling experiment with $\mathrm{H}_{2}^{35} \mathrm{~S}, \mathrm{Na}_{2} \mathrm{~S} \cdot 9 \mathrm{H}_{2} \mathrm{O}$ was not added to the sterilized and purged distilled water in order to maintain sufficient specific activity of dissolved inorganic sulfide. Instead, the distilled water was blended with the redox indicator resazurin (final concentration $=1 \mathrm{mg} \mathrm{L}^{-1}$ ) and reduced slowly with freshly-prepared sodium dithionite solution until the pink color of the liquid indicative for oxic conditions had cleared out completely. Aliquots of sediment slurry of $25 \mathrm{~mL}$ were poured through a funnel into $120 \mathrm{~mL}$ serum vials and amended with $\mathrm{H}_{2}$ and $10 \mathrm{mmol} \mathrm{L}^{-1}$ $\mathrm{NaHCO}_{3}$. Autoclaved slurries $\left(120^{\circ} \mathrm{C}, 25 \mathrm{~min}\right)$ were used as control to account for non-biological reaction and/or processing artifacts.

Radioactive sulfide was produced biologically and purified to remove S-bearing byproducts (T. Holler, unpublished data). The specific activity was $50.9 \mathrm{MBq} \mathrm{mmol}^{-1}$ in the form of $\mathrm{Zn}^{35} \mathrm{~S}$. Each serum vial was supplemented with $\mathrm{H}_{2}^{35} \mathrm{~S}$ gas generated by acidifying a defined volume of $\mathrm{Zn}^{35} \mathrm{~S}$ suspension (equivalent to $59.5 \mathrm{kBq}$ ). The injected $\mathrm{H}_{2}^{35} \mathrm{~S}$ should have resulted in a final hydrogen sulfide concentration of $37 \mu \mathrm{mol} \mathrm{L}^{-1}$ ignoring partitioning into solid $\mathrm{S}$ phases.

To allow for equilibration of $\mathrm{H}_{2}^{35} \mathrm{~S}$ in the serum vials, the time-zero sampling was performed after two hours of incubation. The clear supernatant of the sediment slurry was collected with a plastic syringe fitted with a hypodermic needle, filtered $(0.2 \mu \mathrm{m})$, and the filtrate was injected directly into a $5 \%$ zinc acetate solution for determination of radioactivity in the dissolved fraction and concentration of hydrogen sulfide. The samples for determining hydrogen sulfide concentration were stored at $-20^{\circ} \mathrm{C}$ until analysis. The remaining sediment slurry was treated with $20 \%$ of zinc acetate and $1 \mathrm{mmol} \mathrm{L}^{-1} \mathrm{NaOH}$ and left for two hours at $4{ }^{\circ} \mathrm{C}$ in order to trap $\mathrm{H}_{2} \mathrm{~S}$, MT and carbon disulfide vapors (Adewuyl and Carmichael, 1987) into the liquid or solid phase. We interpreted the remaining volatile radioactivity to represent 
DMS, which was trapped using the method slightly modified from Kiene and Linn (2000). The original butyl stopper on the serum vial was exchanged for a butyl stopper that had an Eppendorf centrifuge vial $(1.5 \mathrm{~mL})$ attached to it. Inside the Eppendorf vial was a strip of Gelman AR glass fiber filter treated with freshly prepared $3 \% \mathrm{H}_{2} \mathrm{O}_{2}$ solution. The serum vials were placed in the dark at room temperature and the sediment slurries were stirred for $>6 \mathrm{~h}$. The traps were then removed, and the strips placed in $5 \mathrm{~mL}$ scintillation vials with scintillation fluid for determination of ${ }^{35} \mathrm{~S}$ radioactivity. Tests with $50 \mu \mathrm{mol} \mathrm{L}{ }^{-1}$ DMS showed that after trapping, DMS decreased to a level below the detection limit of the flame ionization detector. ${ }^{35} \mathrm{~S}$-DMS was not available to determine the exact trapping efficiency, but the trapping efficiency for $\mathrm{H}_{2}^{35} \mathrm{~S}$ in bicarbonate-buffered solution was higher than $90 \%$. The remaining sediment slurries were subjected to a two-step cold distillation (Fossing and Jørgensen, 1989) to investigate the distribution of radioactivity in acid volatile sulfide (AVS: $\mathrm{H}_{2} \mathrm{~S}+\mathrm{FeS}$ ) and chromium reducible sulfur (CRS: $\mathrm{S}^{0}+\mathrm{FeS}_{2}$ ). $N, N$-dimethylformamide was applied in the second step to improve the yield of elemental sulfur (Kallmeyer et al., 2004).

Assuming that only the dissolved fraction could be responsible for formation of methylated sulfides, we calculated the average production rate of DMS derived from doubly methylated hydrogen sulfide $\left(\mathrm{Rate}_{\mathrm{\Sigma}} \mathrm{H}_{2} \mathrm{~S}+2 \mathrm{Me}\right)$ during a labeling period using the following equation

Rate $_{\Sigma \mathrm{H}_{2} \mathrm{~S}+2 M e}=\frac{a_{\text {trap }}}{a_{\mathrm{dis}}} \times\left\{\mathrm{H}_{2} \mathrm{~S}\right\} \times \frac{1}{t}$.

Here Rate $\mathrm{\Sigma H}_{2} \mathrm{~S}+2 \mathrm{Me}$ is expressed as $\mu \mathrm{mol}(\mathrm{L}$ of slurry $)^{-1} \mathrm{~d}^{-1} . \quad a_{\text {trap }}$ is the radioactivity of the trapped pool, $a_{\mathrm{dis}}$ is the activity in the dissolved pool of the sediment slurry, $\left\{\mathrm{H}_{2} \mathrm{~S}\right\}$ is the concentration of hydrogen sulfide per volume of sediment slurry $\left(\mu \mathrm{mol}(\mathrm{L} \text { of slurry })^{-1}\right)$, and $t$ is the number of days during which the reaction was run. Since $\mathrm{H}_{2}^{35} \mathrm{~S}$ is likely to be oxidized into aqueous sulfur oxyanions even under anoxic conditions (Elsgaard and Jørgensen, 1992), $a_{\mathrm{dis}}$ can be an overestimation of the $\mathrm{H}_{2}^{35} \mathrm{~S}$ pool, leading to underestimated values of Rate $\mathrm{\Sigma H}_{2} \mathrm{~S}+2 \mathrm{Me}$.

\subsection{Analytical techniques}

Concentrations of methane and methylated sulfides were determined by headspace analysis. Care was taken to maintain the incubation temperature during gas sampling. An aliquot of $100 \mu \mathrm{L}$ gas was taken from a headspace of 6 to $8 \mathrm{~mL}$ using a Hamilton gas-tight syringe for on-column injection via a programmable temperature vaporizing inlet. A gas chromatograph (Trace GC Ultra, ThermoFinnigan) equipped with a CP-PoraBOND Q (Varian Inc.) column and a flame ionization detector was used to quantify the compounds. The column temperature was programmed from $60{ }^{\circ} \mathrm{C}$ (1 min isothermal) to $240^{\circ} \mathrm{C}(2 \mathrm{~min}$ isothermal $)$ at a rate of $40^{\circ} \mathrm{C} \mathrm{min}{ }^{-1}$. The distribution coefficients for DMS and $\mathrm{MT}$ at $55^{\circ} \mathrm{C}$ are 6.9 and 4.3 , respectively (Przyjazny et al., 1983). Calibration was made with standards prepared anoxically from chemicals. The limits of detection (LOD) were $0.4 \mu \mathrm{mol} \mathrm{L}^{-1}$ for MT and $0.5 \mu \mathrm{mol} \mathrm{L}^{-1}$ for DMS under the described analytical conditions.

For carbon isotope analysis, the same model of GC was coupled to a ThermoFinnigan Delta Plus XP isotope ratio mass spectrometer via a Finnigan combustion interface-III. One milliliter of gas was injected into the split/splitless inlet. A column and a temperature program identical to those described above were used. Values of $\delta^{13} \mathrm{C}$ relative to that for Vienna-PeeDee Belemnite are defined by the equation $\delta^{13} \mathrm{C}(\% o)=\left(R_{\text {sample }} / R_{\text {standard }}-1\right) \times 1000$ with $R={ }^{13} \mathrm{C} /{ }^{12} \mathrm{C}$ and $R_{\text {standard }}=0.0112372 \pm 2.9 \times 10^{-6}$. Internal precision of $\delta^{13} \mathrm{C}$ was better than $\pm 0.1 \%$ (one standard deviation). We used two types of standards to evaluate the isotopic accuracies of methylated sulfides at low concentrations: (1) gaseous standards were prepared by injecting 5 to $550 \mu \mathrm{L}$ of pure standards into helium-flushed, water-free headspace vials that were allowed to equilibrate at $60^{\circ} \mathrm{C}$. Isotopic values of the gaseous standards were not influenced by partition of methylated sulfides into aqueous solution and were taken as "real" values. (2) Solution standards of different concentrations were prepared under a helium headspace with a defined volume of water. By comparing the isotopic values of the solution standards with those of the gaseous standards, we found that at concentrations lower than $5 \mu \mathrm{mol} \mathrm{L}^{-1}$, there was a positive shift for MT (up to $4.5 \%$ ) and a negative shift for DMS (up to $2.5 \%$ ). Since a strict relationship between the correction factor and concentration was not established, we did not correct the $\delta^{13} \mathrm{C}$ values of MT, which had concentrations lower than the threshold during the whole course of the incubation experiments.

Radioactivity was determined by liquid scintillation counting (Packard 2500 TR) with a counting window of 4 to $167 \mathrm{keV}$ without luminescence correction. The scintillation cocktail Lumasafe Plus (Lumac BV, Holland) was mixed with the zinc acetate-fixed dissolved fraction and the glass fiber strips. The counting efficiency was higher than $95 \%$. Counting time was $10 \mathrm{~min}$ for all samples. The concentration of hydrogen sulfide was determined colorimetrically by the methylene blue method (Cline, 1969).

For acetate analysis, sediment slurries in Hungate tubes were centrifuged at $800 \times \mathrm{g}$ for $10 \mathrm{~min}$, and $1 \mathrm{~mL}$ supernatant was removed with a plastic syringe fitted with a 21-gauge needle and filtered through a $0.45-\mu \mathrm{m}$ Rotilabo Teflon syringe filter. The filtrates were stored at $-20^{\circ} \mathrm{C}$ until analysis. Acetate was measured using a high performance liquid chromatograph equipped with a Nucleogel Column (MacheryNagel Inc.) and a photodiode array detector. Calibration curves were generated using standards prepared gravimetrically from sodium acetate. The detection limit for acetate was 10 to $15 \mu \mathrm{mol} \mathrm{L}-1$. 


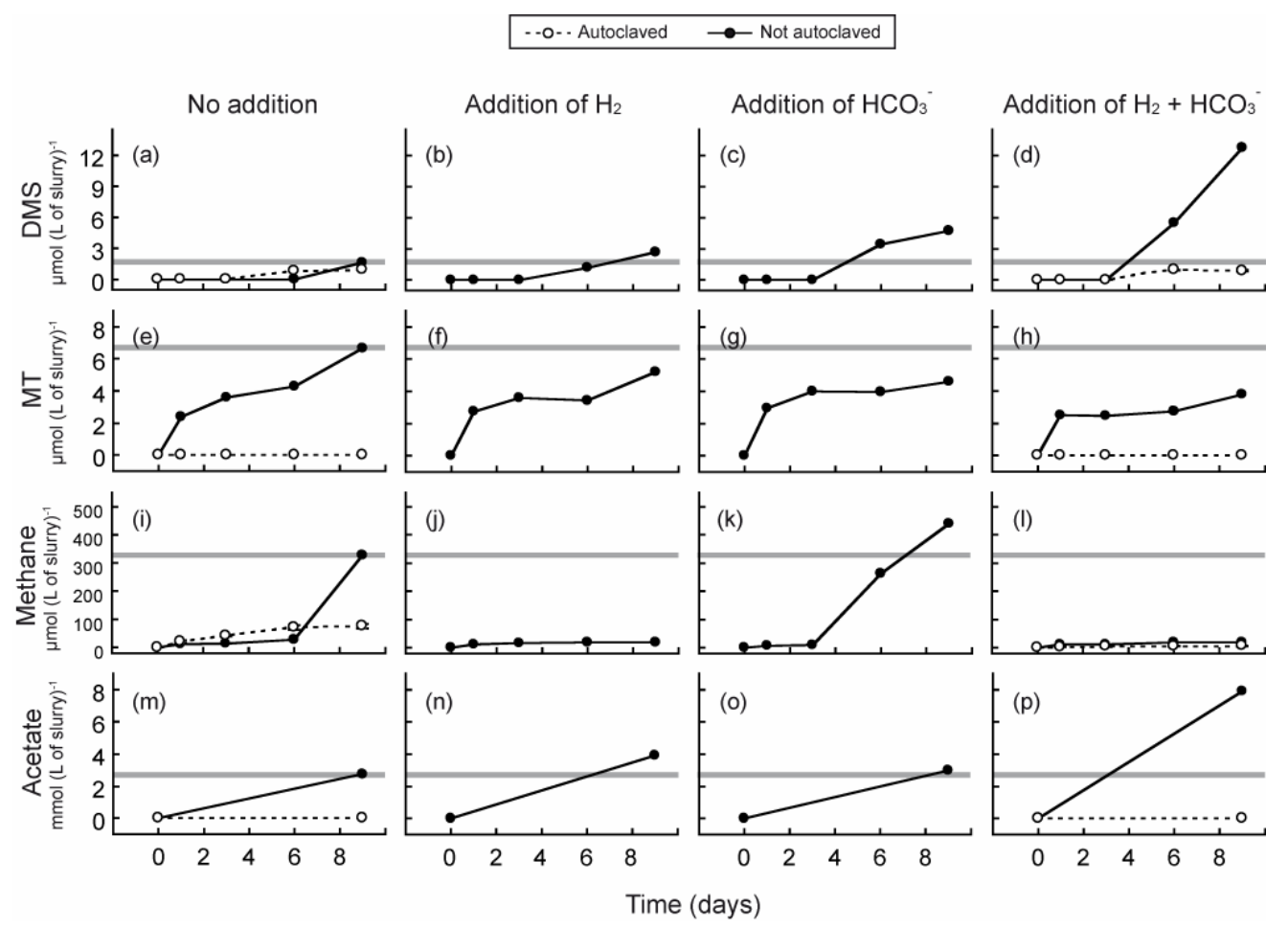

Fig. 2. Effects of $\mathrm{H}_{2}$ and bicarbonate on the formation of dimethyl sulfide (DMS), methanethiol (MT), methane, and acetate in the sediment slurries of Lake Plußsee. Gray lines mark the final concentration of each compound in parallel with the concentration when no substrate was added. Data are from a single sample tube but the pattern is reproducible in similar incubations.

\subsection{Statistical analysis}

The LOD of instrumental methods was assessed statistically by the equation $\mathrm{LOD}=Y_{B}+3 \times \mathrm{S}_{y / x}$, where $Y_{B}$ represents the signal of instrumental background and was estimated by the intercept of a calibration curve, and $S_{y / x}$ stands for the deviation of $Y$ values (see Miller and Miller, 2005, for detailed description). The effect of individual treatments was tested using a one- or two-tailed t test with $\alpha$ set at 0.05 .

\section{Results}

\subsection{Addition of substrates}

In the first experiment, we examined the effects of $\mathrm{H}_{2}$ and bicarbonate on the dynamics of DMS and MT formation at $55^{\circ} \mathrm{C}$. We also monitored the concentrations of methane and acetate, the major carbon pools whose formation can potentially compete for $\mathrm{H}_{2}$ and bicarbonate in this system. Compared to the control without any addition (Fig. 2a), there was no stimulation of DMS accumulation when $\mathrm{H}_{2}$ was added as the single substrate (Fig. 2b). However, addition of bicarbonate resulted in an increase of DMS (Fig. 2c), and simultaneous addition of both $\mathrm{H}_{2}$ and bicarbonate further enhanced DMS accumulation (Fig. 2d). The average accumu- lation rate was $2.1 \mu \mathrm{mol}$ DMS ( $\mathrm{L}$ of slurry $)^{-1} \mathrm{~d}^{-1}$ between days 3 and 9 . Subsequent tests with the same treatment yielded a range of maximal accumulation rates from 1.3 to $2.4 \mu$ mol DMS ( $\mathrm{L}$ of slurry) ${ }^{-1} \mathrm{~d}^{-1}$. Compared to the accumulation of DMS, MT showed the opposite trend. After nine days of incubation the final MT concentration was highest in the control without any substrate addition (Fig. 2e) and lowest when both $\mathrm{H}_{2}$ and bicarbonate were added (Fig. 2h). However, there was no apparent 1:1 stoichiometric ratio for the relationship between MT and DMS. In autoclaved dead controls, MT concentrations were below LOD (Fig. 2e, h), and DMS became detectable only after six days of incubation in the presence of $\mathrm{H}_{2}$ and bicarbonate, but with concentrations being significantly lower than in the active sediment (Fig. 2d). Methane accumulation was suppressed by addition of $\mathrm{H}_{2}$ (Fig. 2j, l) but slightly enhanced by amendment with bicarbonate (Fig. 2k). The acetate concentrations at time zero in the active and autoclaved sediments were both below $10 \mu \mathrm{mol} \mathrm{L}{ }^{-1}$. The effect of $\mathrm{H}_{2}$ and bicarbonate when added separately on acetate formation was minor and negligible, respectively (Fig. 2n, o). In combination, $\mathrm{H}_{2}$ and bicarbonate resulted in a 2.7-fold increase of acetate (Fig. 2p). Note that the concentration of acetate was much higher than DMS, MT and methane by one to three orders of magnitude at the end of incubation. Although addition of bicarbonate alone already enhanced DMS formation (Fig. 2c), in the following 


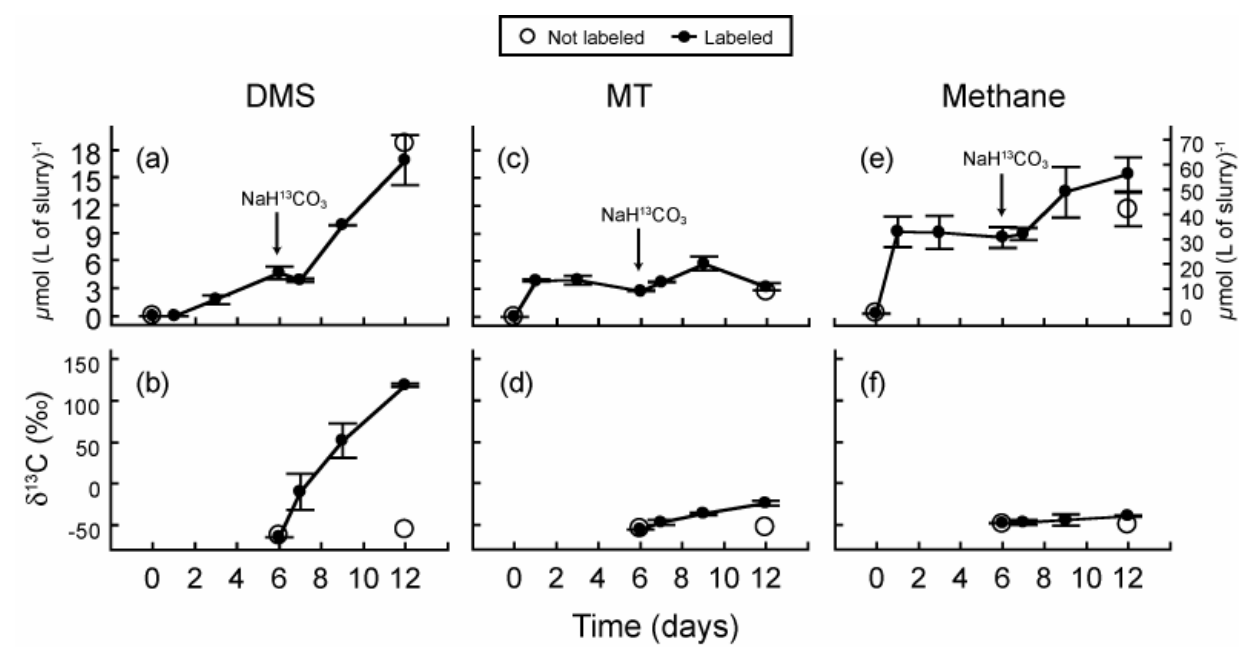

Fig. 3. Concentrations and stable carbon isotopic values of dimethyl sulfide (DMS), methanethiol (MT) and methane in sediment slurries under non-labeling and labeling conditions. $\mathrm{NaH}^{13} \mathrm{CO}_{3}$ was added on day 6 of the incubation. Error bars represent \pm 1 standard error of duplicate tubes.

experiments we added bicarbonate together with $\mathrm{H}_{2}$ in order to obtain higher yields of DMS and to facilitate labeling studies.

To test whether the observed DMS formation was related to the activity of O-demethylation, we examined the effects of sodium sulfide, MT, methanol and syringic acid under either a $\mathrm{N}_{2}$ or a $\mathrm{H}_{2}$ headspace (Table 1). Experimental concentrations of each of these compounds were in the range that stimulated production of DMS and MT in previous studies of freshwater sediment (Lomans et al., 1997; Stets et al., 2004). The results indicated that the presence of $\mathrm{H}_{2}$ and bicarbonate was the major factor leading to increased DMS formation; none of the other four substrates significantly increased DMS formation after 12 days of incubation. The effects of sodium sulfide, methanol or syringic acid on MT formation were either minor or insignificant. The added MT decreased over time and reached $30 \%$ of the initial values after 12 days of incubation. An autoclaved control confirmed that the disappearance of MT was driven by abiological processes (data not shown).

\subsection{Inhibition tests}

Reduction of bicarbonate with $\mathrm{H}_{2}$ in anoxic sediment is commonly associated with activities of either acetogens or methanogens. Acetogenesis was very active in our incubated sediment but could not be specifically inhibited to examine the corresponding effects on formation of methylated sulfides. However, the role of methanogens can be evaluated by BES, an inhibitor for methanogenesis (Chidthaisong and Conrad, 2000). Relative to the positive control (Table 2), DMS formation was $60 \%$ inhibited by $20 \mathrm{mmol} \mathrm{L}^{-1}$ $\operatorname{BES}(P=0.024$, one-tailed t-test), whereas MT accumula- tion increased slightly $(P=0.044$, one-tailed t-test). Since methane production was already suppressed in the presence of high $\mathrm{H}_{2}$ partial pressure (Fig. 2i-1), BES did not significantly lower the methane level ( $P=0.182$, one-tailed t-test $)$ in this experiment in which $200 \mathrm{kPa} \mathrm{H}_{2}$ was applied. BES had no effect on the formation of acetate.

\subsection{Stable carbon isotopic compositions under non-labeling and ${ }^{13} \mathrm{C}$ labeling conditions}

The stable carbon isotopic compositions of methylated sulfides provide additional evidence on the enzymatic pathways involved in their formation. Under the non-labeling condition, DMS was ${ }^{13} \mathrm{C}$-depleted with $\delta$-values as negative as $-62 \%$ on day 6 , and increased slightly to $-56 \%$ at the end of incubation (Fig. 3b). The analyzed $\delta^{13} \mathrm{C}$ values of MT were $-55 \%$ and $-53 \%$ on days 6 and 12 (Fig. 3d), respectively, but the actual $\delta^{13} \mathrm{C}$ values of MT should have been more negative, since the MT concentrations were below the threshold value of $5 \mu \mathrm{mol} \mathrm{L}{ }^{-1}$ (cf. Materials and Methods). Methane production was low and the $\delta^{13} \mathrm{C}$ values remained around $-50 \%$ o during the course of incubation (Fig. $3 \mathrm{f}$ ).

In parallel, we performed a ${ }^{13} \mathrm{C}$-labeling experiment with $\mathrm{NaH}^{13} \mathrm{CO}_{3}$ to investigate the incorporation of bicarbonate into DMS. If bicarbonate was used directly to form one of the methyl groups in DMS rather than exerting an indirect effect that favored DMS formation (e.g., via buffering the aqueous solution), we would expect rapid labeling after $\mathrm{NaH}^{13} \mathrm{CO}_{3}$ was added. The experimental results showed that DMS became enriched in ${ }^{13} \mathrm{C}$ by nearly $40 \%$ already one day after label addition. The ${ }^{13} \mathrm{C}$ enrichment of DMS increased to $181 \%$ after 12 days with DMS having a final $\delta^{13} \mathrm{C}$-value of $+119 \%$ (Fig. 3b). Assuming no consumption of DMS, we 
Table 1. Concentrations of DMS and MT after 12 days of incubation with inorganic and organic substrates. Results are presented as means and standard errors from duplicate tubes.

\begin{tabular}{llll}
\hline Treatment & Headspace & DMS $\mu$ mol (L of slurry) $)^{-1}$ & MT $\mu$ mol (L of slurry) $)^{-1}$ \\
\hline No addition & $\mathrm{N}_{2}$ & $3.7 \pm 1.7$ & $3.0 \pm 1.7$ \\
Methanol, $800 \mu \mathrm{mol} \mathrm{L}^{-1}$ & $\mathrm{~N}_{2}$ & $1.5 \pm 0.1$ & $2.6 \pm 0.2$ \\
Syringic acid, $100 \mu \mathrm{mol} \mathrm{L}^{-1}$ & $\mathrm{~N}_{2}$ & $1.1 \pm 0.4$ & $2.7 \pm 0.1$ \\
No addition & $\mathrm{H}_{2}\left(+\mathrm{HCO}_{3}^{-}\right)$ & $11.1 \pm 0.3$ & $2.8 \pm 0.1$ \\
Sodium sulfide, $200 \mu \mathrm{mol} \mathrm{L}^{-1}$ & $\mathrm{H}_{2}\left(+\mathrm{HCO}_{3}^{-}\right)$ & $9.6 \pm 1.0$ & $4.4 \pm 1.6$ \\
Methanethiol, $50 \mu \mathrm{mol} \mathrm{L}^{-1}$ & $\mathrm{H}_{2}\left(+\mathrm{HCO}_{3}^{-}\right)$ & $9.1 \pm 0.6$ & $14.8 \pm 4.2$ \\
Methanol, $800 \mu \mathrm{mol} \mathrm{L}^{-1}$ & $\mathrm{H}_{2}\left(+\mathrm{HCO}_{3}^{-}\right)$ & $3.7 \pm 0.4$ & $4.3 \pm 0.1$ \\
Syringic acid, $100 \mu \mathrm{mol} \mathrm{L}^{-1}$ & $\mathrm{H}_{2}\left(+\mathrm{HCO}_{3}^{-}\right)$ & $6.8 \pm 0.5$ & $3.8 \pm 0.4$ \\
\hline
\end{tabular}

Table 2. Effects of $20 \mathrm{mmol} \mathrm{L}^{-1}$ 2-bromoethanesulfonate (BES) on formation of dimethyl sulfide, methanethiol, methane and acetate after 12 days of incubation. The sediments slurries were added with $200 \mathrm{kPa} \mathrm{H}_{2}$ and $10 \mathrm{mmol} \mathrm{L}^{-1}$ bicarbonate. Results are presented as means and standard errors from duplicate tubes.

\begin{tabular}{|c|c|c|}
\hline Compounds & Positive control & $+\mathrm{BES}$ \\
\hline $\begin{array}{l}\text { Dimethyl sulfide, } \\
\mu \mathrm{mol}(\mathrm{L} \text { of slurry) }\end{array}$ & $11.7 \pm 0.3$ & $4.2 \pm 2.2$ \\
\hline $\begin{array}{l}\text { Methanethiol, } \\
\mu \mathrm{mol}(\mathrm{L} \text { of slurry })^{-1}\end{array}$ & $3.1 \pm 0.1$ & $4.7 \pm 0.8$ \\
\hline $\begin{array}{l}\text { Methane, } \\
\mu \mathrm{mol}(\mathrm{L} \text { of slurry })^{-1}\end{array}$ & $48.2 \pm 16.9$ & $32.8 \pm 8.2$ \\
\hline $\begin{array}{l}\text { Acetate, } \\
\text { mmol (L of slurry })^{-1}\end{array}$ & $6.4 \pm 0.3$ & $6.7 \pm 0.4$ \\
\hline
\end{tabular}

calculated the ${ }^{13} \mathrm{C}$ abundance of the newly fixed carbon into DMS based on the measured size and $\delta$-values of the DMS pool at different time points. The results showed that (1) if both methyl groups were derived from bicarbonate, the average ${ }^{13} \mathrm{C}$ abundance of the newly fixed carbon was $1.3 \%$ during the period after labeling addition, and (2) if only one methyl group was involved, the average ${ }^{13} \mathrm{C}$ abundance of the newly fixed carbon would raise to $2.6 \%$. These estimates are consistent with at least one methyl group being derived from the $\mathrm{NaH}^{13} \mathrm{CO}_{3}$ spiked DIC pool ( $\sim 2 \%{ }^{13} \mathrm{C}$ abundance).

MT showed a much slower but significant $(P=0.002$, one-tailed t-test) enrichment, and reached $-24 \%$ o by the end of the experiment. ${ }^{13} \mathrm{C}$-enrichment of methane was merely 9\%o (Fig. 3f), a finding that agrees with our observation that methanogenesis via reduction of $\mathrm{CO}_{2}$ was low.

\subsection{Labeling with $\mathrm{H}_{2}^{35} \mathrm{~S}$}

The result of the ${ }^{13} \mathrm{C}$-labeling experiment indicated incorporation of bicarbonate with MT, but the source of MT remains unclear. The effects of sodium sulfide, methanol and syringic acid on MT formation, if any, might have been too small to

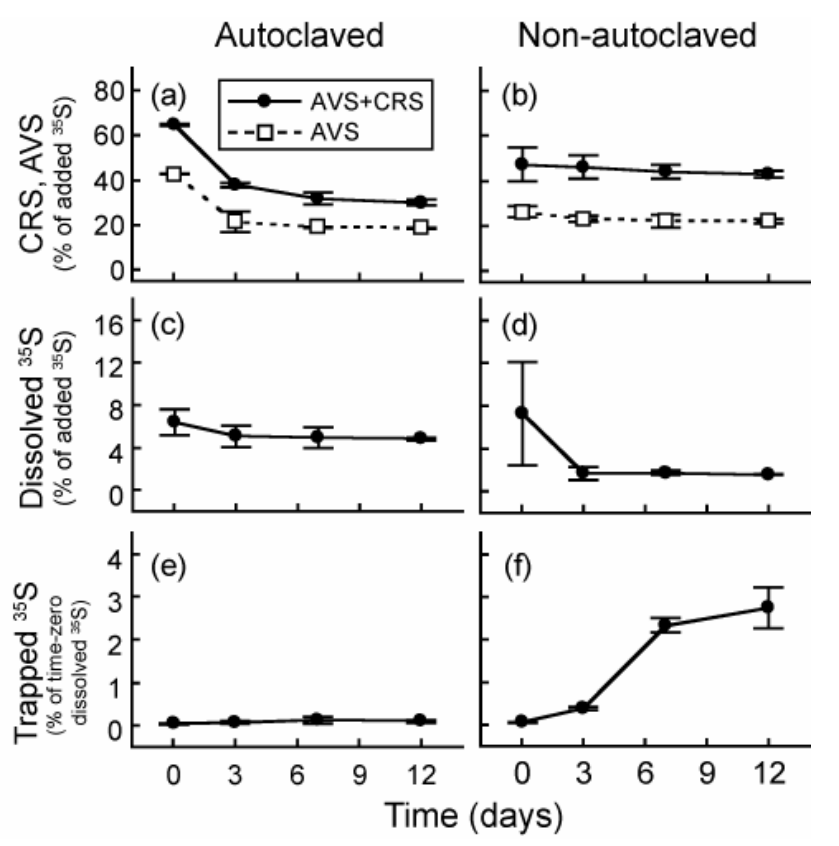

Fig. 4. Distribution of radioactivity in the sediment slurries of Lake Plußsee during incubation with $\mathrm{H}_{2}$, bicarbonate and $\mathrm{H}_{2}^{35}$ S. Timezero values were measured two hours after addition of radiotracer. AVS: acid volatile sulfide $\left(\mathrm{H}_{2} \mathrm{~S}+\mathrm{FeS}\right)$; CRS: chromium reducible sulfur $\left(\mathrm{S}^{0}+\mathrm{FeS}_{2}\right)$. The dissolved ${ }^{35} \mathrm{~S}$ was measured from filtered slurry supernatant. The trapped ${ }^{35} \mathrm{~S}$ was interpreted to represent labeled dimethyl sulfide. Error bars represent \pm 1 standard error of duplicate bottles.

be resolved by changes in MT concentration (Table 1), and the slight ${ }^{13} \mathrm{C}$ enrichment of MT in the labeling experiment is not conclusive proof for methylation of hydrogen sulfide by reduced bicarbonate. With the radiotracer experiment with $\mathrm{H}_{2}^{35} \mathrm{~S}$, we sought to better characterize the reaction of formation of DMS - via the intermediate MT - from hydrogen sulfide. The MT pool targeted in this experiment may derive from the reactions of hydrogen sulfide with inorganic carbon or non-S-methyl compounds such as O-methyl pools (Fig. 1). 
At time zero (after two hours of incubation), the dissolved fraction contained less than $10 \%$ of total added radioactivity (Fig. 4c, d). A significant amount of $\mathrm{H}_{2}^{35} \mathrm{~S}$ entered the solid phase AVS (most likely FeS) and CRS fractions via isotope exchange (Figs. 4a, 4b; Fossing et al., 1992). The trapped radioactivity in non-autoclaved samples was much higher than in the autoclaved control (Fig. 4e, f; $P=0.008$, one-tailed t-test), suggesting that DMS formed biologically. In the non-autoclaved samples, the trapped radioactivity increased most rapidly between days 3 and 7 and finally reached $2.5 \%$ of the dissolved radioactivity. We obtained an average Rate $\Sigma_{\mathrm{H}_{2} \mathrm{~S}+2 \mathrm{Me}}$ of $0.06 \mu \mathrm{mol}(\mathrm{L} \text { of slurry })^{-1} \mathrm{~d}^{-1}$ over the whole period of incubation and a higher rate of $0.1 \mu \mathrm{mol}(\mathrm{L}$ of slurry $)^{-1} \mathrm{~d}^{-1}$ between days 3 and 7 . The rates are in the range of reported sulfide-dependent MT production rates in freshwater sediment at low hydrogen sulfide concentrations (Lomans et al., 1997), but represent $<10 \%$ of the ambient DMS production rate determined by the kinetics of total DMS formation in this study.

\section{Discussion}

Our experimental data showed that both DMS and MT were of biogenic origin and depleted in ${ }^{13} \mathrm{C}$. However, both compounds responded differently to addition of substrates and inhibitors, and exhibited different patterns of ${ }^{13} \mathrm{C}$ incorporation. Therefore, DMS and MT formation will be discussed separately, followed by a note on the implication of these processes for natural anoxic environments.

\subsection{Microbial DMS formation}

Our observation indicates that dissolved inorganic carbon in anoxic aquatic environments can be incorporated into DMS: $\mathrm{H}_{2}$ alone did not stimulate DMS formation while bicarbonate alone did, and both together stimulated DMS even more; MT accumulated slightly when DMS production was hindered by the lack of $\mathrm{H}_{2}$ and bicarbonate or by the addition of $\mathrm{BES} ;{ }^{13} \mathrm{C}$-labeled bicarbonate was incorporated much more rapidly into DMS than into MT. These facts suggest the following reaction:

$$
\begin{aligned}
& \mathrm{HCO}_{3}^{-}+\mathrm{H}^{+}+3 \mathrm{H}_{2}+\mathrm{CH}_{3} \mathrm{SH} \rightarrow \mathrm{CH}_{3} \mathrm{SCH}_{3}+3 \mathrm{H}_{2} \mathrm{O} \\
& \Delta G^{\circ \prime}=-159.8 \mathrm{~kJ} \text { per reaction }
\end{aligned}
$$

The standard-state free energy for the proposed reaction was calculated using thermodynamic data for aqueous species listed in Scholten et al. (2003). The production rate is consistent with the previously observed kinetics in other freshwater environments (Lomans et al., 1997; Stets et al., 2004). Addition of MT did not further stimulate DMS formation (Table 1), suggesting that this process is not limited by MT. Since addition of methanol or syringic acid failed to stimulate DMS production, this process is not related to Odemethylation.
DMS under the non-labeling condition was ${ }^{13} \mathrm{C}$-depleted with $\delta$-values as negative as $-62 \%$ (Fig. 3b). According to Eq. (2), one of the methyl groups was from MT and the other from reduced bicarbonate. Since the measured $\delta^{13} \mathrm{C}$ value of MT in experiments without label addition was around $-54 \%$ o, a simple mixing model provides a rough estimate of $-70 \%$ for the $\delta^{13} \mathrm{C}$ value of the methyl group from reduced bicarbonate. Compared with the $\delta^{13} \mathrm{C}$ value of the added $\mathrm{NaHCO}_{3}\left(-2.2 \%\right.$; data not shown), the strong ${ }^{13} \mathrm{C}$ depletion of the methyl group is consistent with a kinetic isotopic effect typical for $\mathrm{H}_{2} / \mathrm{CO}_{2}$ metabolizers such as autotrophic methanogens (Whiticar, 1999) or acetogens (Gelwicks et al., 1989).

Suppression of DMS production by BES further suggests that methanogens are involved in DMS formation. Moran et al. (2008) previously discussed the enzymatic steps of $M$. acetivorans to produce methylated sulfides. We hypothesize that the same pathway is active with $\mathrm{CO}_{2}$ rather than $\mathrm{CO}$ as the direct precursor (Fig. 5). Normally, coenzyme M (CoM-SH) receives the methyl group from $N^{5}$ methyl- $\mathrm{H}_{4}$ MPT:CoM-SH methyltransferase (Mtr) complex to form methyl-CoM, which releases methane by forming heterodisulfide with coenzyme $\mathrm{B}(\mathrm{CoB}-\mathrm{SH})$ by the catalysis of methyl-CoM reductase (Mcr). Under the condition of DMS production, the methyl group is transferred from methyl-CoM to MT, a reaction that is the reverse of the CoM methylation step employed by DMS-consuming methanogens (Hedderich and Whitman, 2006). As Moran et al. (2008) pointed out, such a shortcut to regenerate CoM$\mathrm{SH}$ is feasible, owing to the low energy barrier in the activation step of methanogenic DMS consumption by methylthiol:CoM methyltransferase (Mts) $\left(\Delta G^{\circ \prime}=0.35 \mathrm{~kJ}\right.$ per reaction; Tallant et al., 2001). The overall energy yield for the methanogenic DMS production is theoretically lower than normal methanogenesis, as the $\mathrm{H}^{+}$-pumping step of heterodisulfide reduction is bypassed and energy conservation is restricted to the $\mathrm{Na}^{+}$-pumping Mtr complex (Hedderich and Whitman, 2006). From an energetic point of view, therefore, DMS might be considered as a by-product of inefficient methanogenesis.

DMS formation may also be a response to environmental stress. For instance, Moran et al. (2008) attributed the production of methylated sulfides by $M$. acetivorans to the high $\mathrm{CO}$ concentration $(300 \mathrm{kPa})$ in their cultures. CO likely inhibits Mcr, causing CoM-SH to be sequestered and energy production stopped. Transferring the methyl group to hydrogen sulfide or MT can be a shortcut to regenerate CoM$\mathrm{SH}$ while bypassing Mcr. In our incubation, the headspace $\mathrm{CO}$ concentrations were lower than $0.5 \mathrm{~Pa}$ (data not shown) and were unlikely to have a marked inhibitory effect. Nevertheless, the methane accumulation rates at $55^{\circ} \mathrm{C}$ in Lake Plußsee sediment were indeed much lower by one to two orders of magnitude than rates at $27^{\circ}$ and $40^{\circ} \mathrm{C}$ (data not shown). This suggests that, while the mesophilic community was under high temperature stress, an activation of a 


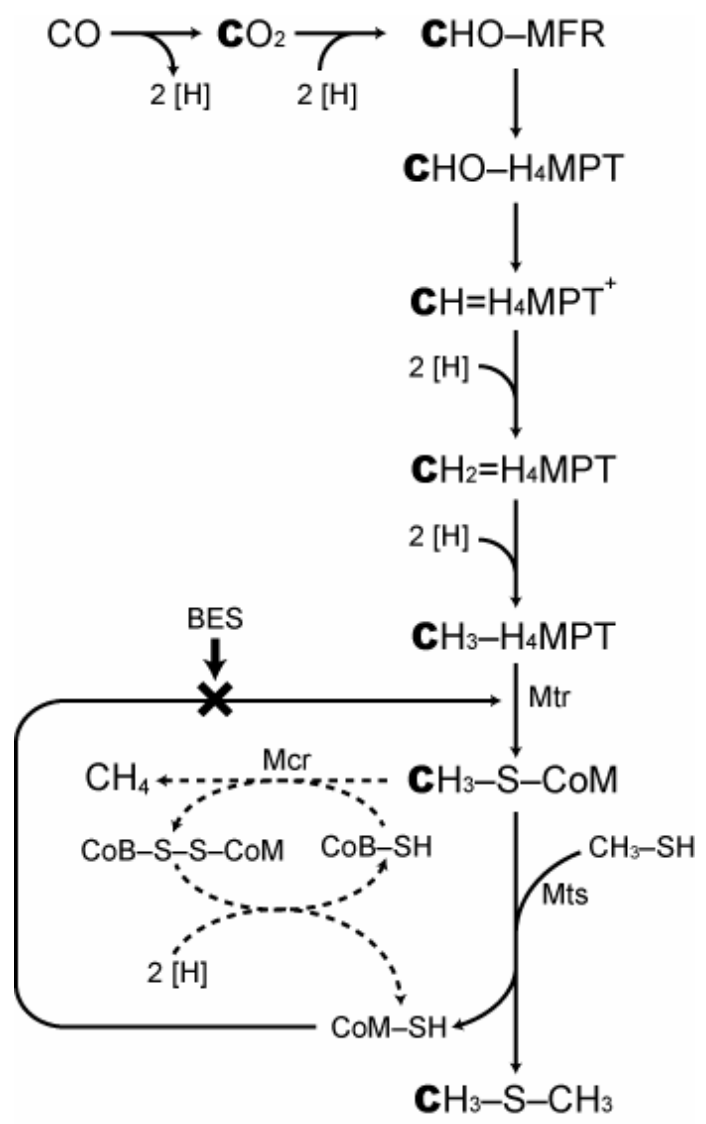

Fig. 5. A simplified scheme of methanogenic dimethyl sulfide (DMS) formation. The formation of DMS from carbon monoxide (CO) is reported in Moran et al. (2008). The carbon atoms highlighted in bold type refer to the process proposed in this study, i.e., formation of DMS from $\mathrm{CO}_{2}$. The dashed arrows are pathways that are bypassed when DMS rather than methane is produced. The enzymatic step inhibited by 2-bromoethanesulfonic acid (BES) is marked with a cross. Abbreviations: MFR, methanofuran; $\mathrm{H}_{4} \mathrm{MPT}$, tetrahydromethanopterin; CoM-SH, coenzyme $\mathrm{M} ; \mathrm{CH}_{3}-$ S-CoM, methyl coenzyme M; CoB-SH, coenzyme B; Mtr, $N^{5}$ methyl- $\mathrm{H}_{4} \mathrm{MPT}$ :CoM-SH methyltransferase; Mcr, methyl-CoM reductase; Mts, methylthiol:CoM methyltransferase.

thermophilic population of methanogens did not occur. The elevated temperature may have also improved the availability of substrates such as MT, $\mathrm{CO}_{2}$ and $\mathrm{H}_{2}$ via acceleration of organic matter breakdown, making the DMS-forming pathway thermodynamically feasible for methanogens. Nevertheless, growth by this mechanism remains to be determined, even if it is thermodynamically feasible.

We note that high $\mathrm{H}_{2}$ partial pressure, which favored DMS formation when added together with bicarbonate, failed to stimulate methanogenesis during our incubation (Fig. 2). A similar lack of methanogenesis was also found in previous incubation experiments with Lake Plußsee sediments that used $\mathrm{H}_{2}$ rich gas mixture (80:20 $\left.\mathrm{H}_{2} / \mathrm{CO}_{2}\right)$ but lower temperatures
( $4^{\circ}$ and $25^{\circ} \mathrm{C}$ ) (Nüsslein and Conrad, 2000; Heuer et al., 2010), while incubation under $4 \% \mathrm{H}_{2}$ headspace enhanced methanogenic activity (Nüsslein and Conrad, 2000). The reasons why methanogenesis is stimulated successfully with addition of low $\mathrm{H}_{2}$ concentrations but not with high concentrations remain to be explored. Although our data do not provide evidence that would help to explain this phenomenon, we demonstrated that under the condition of high $\mathrm{H}_{2}$ partial pressure and elevated temperature, a fraction of $\mathrm{H}_{2}$ and $\mathrm{CO}_{2}$ still enter the methanogenic pathway but with DMS as the final product.

Sequences retrieved from fresh Lake Plußsee sediment using the mcrA-gene primer showed the greatest homology with members of the Methanomicrobiales (Heuer et al., 2010), which are strict $\mathrm{H}_{2} / \mathrm{CO}_{2}$ metabolizers and are unlikely to possess Mts required for the transfer of methylated sulfides (Fig. 5). Therefore, it is likely that the observed DMS formation was performed by a minor population of methanogens that, like some members of the Methanosarcinales, are capable of using both $\mathrm{H}_{2} / \mathrm{CO}_{2}$ and methylated sulfides (Kendal and Boone, 2006).

\subsection{Microbial MT formation}

Autoclaved controls confirmed that MT in our system is also of biological origin, and the natural $\delta^{13} \mathrm{C}$-values are very negative $(<-50 \%)$. In contrast to some previous studies suggesting that methyl transfer from methoxylated aromatic compounds to hydrogen sulfide is a main source of MT in freshwater sediment (Lomans et al., 1997, 2002), addition of sodium sulfide, methanol and syringic acid to our microcosm failed to stimulate MT formation. By labeling with $\mathrm{H}_{2}^{35} \mathrm{~S}$ we were able to quantify the inventory of methylated hydrogen sulfide that finally entered the DMS pool. The minor supply of MT derived directly from hydrogen sulfide does not support the accumulation rate of DMS that is supposed to derive from MT (Eq. (2)). Taken together, our experiments suggest that the DMS production proceeded via MT derived mostly from organic-S pools. However, from these experiments we can not yet identify the mechanism of MT formation.

Nevertheless, the carbon isotopic composition of MT at natural abundance levels is intriguing and deserves further discussion. The main question is: How can we explain the ${ }^{13} \mathrm{C}$ depletion of MT that we observed under the nonlabeling condition? Hydrogenotrophic bicarbonate reduction is usually considered the main process that generates the ${ }^{13} \mathrm{C}$ depleted methyl group. If the slight enrichment of MT in the ${ }^{13} \mathrm{C}$-labeling experiment reflects the signal of bicarbonate incorporation (Fig. 3), the contribution of bicarbonate reduction must be very minor, otherwise the small carbon pool of MT and its inferred rapid turnover should have allowed a pronounced labeling signal. Alternatively, demethylation of ${ }^{13} \mathrm{C}$-labeled DMS may also explain the slight enrichment of MT if there was a tight coupling between production and consumption of MT. However, since a substantial fraction of 
MT is lost to other reactions (cf. Sect. 3.1) there must have been some other major source. A second possible source of a ${ }^{13} \mathrm{C}$-depleted methyl group would be methoxylated aromatic compounds: Keppler et al. (2004) reported that the methyl pool in lignin has $\delta^{13} \mathrm{C}$ values as negative as $-66 \%$. This possibility is nevertheless not supported by our results from the substrate tests and $\mathrm{H}_{2}^{35} \mathrm{~S}$-labeling experiment. A last potential source that has received little attention but cannot be ruled out is the S-methyl pool of amino acids. MT accumulated rapidly after addition of methionine in the Plußsee sediment (data not shown), but we have no information on the pool size of free methionine and its endogenesis from enzymatic hydrolysis of macromolecules. According to a study on the carbon isotopic pattern in purine alkaloids in higher plants (Weilacher et al., 1996), the methyl pool in S-adenosylmethionine, a coenzyme with its methyl group derived from methionine, showed a moderate ${ }^{13} \mathrm{C}$-depletion $\left(\delta^{13} \mathrm{C}<-39 \%\right.$ ). If methionine has an identical carbon isotopic composition in its methyl group, it could be another source for a moderately ${ }^{13} \mathrm{C}$-depleted methyl pool. Additionally, methionine and $\mathrm{S}$-adenosylmethionine are involved in biosynthesis of many O- and S-methyl pools in organic matter, including DMSP and lignin monomers. Direct isotopic analysis of the methyl group in methionine will be essential to better constrain the propagation and distribution of $\delta^{13} \mathrm{C}$ signatures of $\mathrm{C} 1$ compounds in nature, including methylated sulfides.

\subsection{Implications for anoxic environments}

Although our experimental temperature hinders implications for the local biogeochemistry of the lake, the incorporation of bicarbonate into DMS may be relevant to several anoxic environments. The fact that this process was more easily observed at elevated temperature in our incubations makes geothermally influenced subsurface sediments and hydrothermal vents a potential target for future studies on this topic. For example, as summarized in Fig. 1, abiotic synthesis of alkylated sulfides has been demonstrated in the laboratory and is considered relevant for hydrothermal environments. A recent study on in situ measurements further demonstrated considerable amounts of MT in a hydrothermal area (Reeves and Seewald, 2009). The supply of MT, the usually high chemical potential of $\mathrm{H}_{2}$ and bicarbonate, and, possibly, elevated temperature, qualify hydrothermal systems as candidate ecosystems in which the DMS-forming process characterized in this study could take place.

However, the possibility to detect such a process at lower temperatures should not be excluded. We suggested that the high temperature during incubation facilitates this reaction by increasing the availability of substrates $\left(\mathrm{MT}, \mathrm{CO}_{2}\right.$ and $\left.\mathrm{H}_{2}\right)$ to methanogens. If this is true and elevated temperature is not a prerequisite, there are low-temperature environments with similar chemical conditions in the real world that deserve further examination. One setting is the sulfate-methane transition zone (SMTZ) in marine sediments associated with AOM activity (e.g., Hoehler et al., 2000). It is a particular zone where sulfate is exhausted and methane from underlying sediment is consumed. Additionally, this zone is often accompanied by peak hydrogen sulfide and bicarbonate concentrations. Laboratory experiments demonstrated that during the transition from sulfate reduction to methanogenesis, there is a decoupling of $\mathrm{H}_{2}$ production and consumption and hence a temporary accumulation of $\mathrm{H}_{2}$ (Hoehler et al., 1999). Isotopic evidence for acetogenesis via $\mathrm{CO}_{2}$ reduction in an extended sediment interval just below the SMTZ at the Cascadia Margin is also consistent with elevated $\mathrm{H}_{2}$ concentration in situ (Heuer et al., 2009). If there are sources of MT, e.g., transmethylation from lignin monomer to hydrogen sulfide, the SMTZ qualifies as an additional environment where DMS formation by methanogens is thermodynamically favorable.

\section{Conclusions}

In this study, we investigated the formation of DMS and MT in anoxic lake sediment at elevated temperature. On the one hand, we provided multiple lines of evidence for a novel microbial pathway of DMS production in anoxic lake sediment. This pathway connects DMS to bicarbonate and $\mathrm{H}_{2}$ and is mediated by methanogens. Subsequent investigations will have to characterize the physiological conditions under which methanogens favor production of DMS and other methylated sulfides rather than methane, and to explore the environmental relevance of this novel pathway. On the other hand, our data could not identify the mechanism of MT formation despite various experimental attempts. This illustrates a more complicated biogeochemistry of MT, which will remain a great challenge for future research.

Acknowledgements. We thank M. Krüger and G. Eller for providing the sediment; C. Deusner for producing radio-labeled sulfide for the first round of the radiotracer experiment; K. Imhoff for performing cold distillation of the samples; L. Wehrmann for the instruction of sulfide determination; M. Elvert and X. Prieto Mollar for assisting the carbon isotopic analysis of gases. We would like to address our gratitude to T. Holler for providing radio-labeled sulfide for the second round of the radiotracer experiment and for his comments on an earlier version of the manuscript. We would like to cordially thank R. Kiene and J. Pohlman for their careful and stimulating reviews of this manuscript. This work was supported by the DFG-Research Center/Excellence Cluster "The Ocean in the Earth System" (MARUM), the Deutscher Verband Flüssiggas (DVFG), and the Max Planck Society. YSL was co-sponsored by the Bremen International Graduate School for Marine Sciences (GLOMAR).

Edited by: J. Middelburg 


\section{References}

Adewuyl, Y. G. and Carmichael, G. R.: Kinetics of hydrolysis and oxidation of carbon disulfide by hydrogen peroxide in alkaline medium and application to carbonyl sulfide, Environ. Sci. Technol., 21, 170-177, 1987.

Charlson, R. J., Lovelock, J. E., Andreae, M. O., and Warren, S. G.: Oceanic phytoplankton, atmospheric sulphur, cloud albedo and climate, Nature, 326, 655-661, 1987.

Chidthaisong, A. and Conrad, R.: Specificity of chloroform, 2bromoethanesulfonate and fluoroacetate to inhibit methanogenesis and other anaerobic processes in anoxic rice field soil, Soil Biol. Biocem., 32, 977-988, 2000.

Cline, J. D.: Spectrophotometric determination of hydrogen sulfide in natural waters, Limnol. Oceanogr., 14, 454-458, 1969.

Eller, G., Känel, L., and Krüger, M.: Cooccurrence of aerobic and anaerobic methane oxidation in the water column of Lake Plußsee, Appl. Environ. Microbiol., 71, 8925-8928, 2005.

Elsgaard, L. and Jørgensen, B. B.: Anoxic transformations of radiolabeled hydrogen sulfide in marine and freshwater sediments, Geochim. Cosmochim. Acta, 56, 2425-2435, 1992.

Ferdelman, T. G., Church, T. M., and Luther III, G. W.: Sulfur enrichment of humic substances in a Delaware salt marsh sediment core, Geochim. Cosmochim. Acta, 55, 979-988, 1991.

Fossing, H. and Jørgensen, B. B.: Measurement of bacterial sulfate reduction in sediments: Evaluation of a single-step chromium reduction method, Biogeochemistry, 8, 205-222, 1989.

Fossing, H., Thode-Andersen, S., and Jørgensen, B. B.: Sulfur isotope exchange between ${ }^{35} \mathrm{~S}$-labeled inorganic sulfur compounds in anoxic marine sediments, Mar. Chem., 38, 117-132, 1992.

Gelwicks, J. T., Risatti, J. B., and Hayes, J. M.: Carbon isotope effects associated with autotrophic acetogenesis, Org. Geochem., 14, 441-446, 1989.

Hedderich, R. and Whitman, W. B.: Physiology and biochemistry of the methane-producing archaea, Prokaryotes, 2, 1050-1079, 2006.

Heinen, W. and Lauwers, A. M.: Organic sulfur compounds resulting from the interaction of iron sulfide, hydrogen sulfide and carbon dioxide in an anaerobic aqueous environment, Origins Life Evol. Biosphere, 26, 131-150, 1996.

Heuer, V. B., Krüger, M., Elvert, M., and Hinrichs, K.-U.: Experimental studies on the stable carbon isotope biogeochemistry of acetate in lake sediments, Org. Geochem., 41, 22-30, 2010.

Heuer, V. B., Pohlman, J. W., Torres, M. E., Elvert, M., and Hinrichs, K.-U.: The stable carbon isotope biogeochemistry of acetate and other dissolved carbon species in deep subsurface sediments at the northern Cascadia Margin, Geochim. Cosmochim. Acta, 73, 3323-3336, 2009.

Hoehler, T. M., Albert, D. B., Alperin, M. J., and Martens, C. S.: Acetogenesis from $\mathrm{CO}_{2}$ in an anoxic marine sediment, Limnol. Oceanogr., 44, 662-667, 1999.

Hoehler, T. M., Borowsky, W. S., Alperin, M. J., Rodrigeuz, N. M., and Paull, C. K.: Model, stable isotope, and radiotracer characterization of anaerobic methane oxidation in gas hydrate-bearing sediments of the Blake Ridge, in: Proc. ODP, Sci. Results, edited by: Paull, C. K., Matsumoto, R., Wallace, P. J., and Dillon, W. P., 164, College Station, TX, 79-85, 2000.

Huber, C. and Wächtershäuser, G.: Activated acetic acid by carbon fixation on (Fe, Ni)S under primordial conditions, Science, 276, 245-247, 1997.
Kallmeyer, J., Ferdelman, T. G., Weber, A., Fossing, H., and Jørgensen, B. B.: A cold chromium distillation procedure for radiolabeled sulfide applied to sulfate reduction measurements, Limnol. Oceanogr. Meth., 2, 171-180, 2004.

Kendall, M. M. and Boone, D. R.: The order Methanosarcinales, Prokaryotes, 3, 244-256, 2006.

Keppler, F., Kalin, R. M., Harper, D. B., McRoberts, W. C., and Hamilton, J. T. G.: Carbon isotope anomaly in the major plant $\mathrm{C} 1$ pool and its global biogeochemical implications, Biogeosciences, 1, 123-131, doi:10.5194/bg-1-123-2004, 2004.

Kiene, R. P., and Linn, L. J.: The fate of dissolved dimethylsulfoniopropionate (DMSP) in seawater: Tracer studies using ${ }^{35} \mathrm{~S}$ DMSP, Geochim. Cosmochim. Acta, 64, 2797-2810, 2000.

Kiene, R. P., Linn, L. J., González, J., Moran, M. N., and Bruton, J. A.: Dimethylsulfoniopropionate and methanethiol are important precursors of methionine and protein-sulfur in marine bacterioplankton, Appl. Environ. Microbiol., 65, 4549-4558, 1999.

Kiene, R. P., Malloy, K. D., and Taylor, B. F.: Sulfur-containing amino acids as precursors of thiols in anoxic coastal sediments, Appl. Environ. Microbiol., 56, 156-161, 1990.

Lomans, B. P., Maas, R., Luderer, R., Op den Camp, H. J. M., Pol, A., van der Drift, C., and Vogels, G. D.: Isolation and characterization of Methanomethylovorans hollandica gen. nov., sp. nov., isolated from freshwater sediment, a methylotrophic methanogen able to grow on dimethyl sulfide and methanethiol, Appl. Environ. Microbiol., 65, 3641-3650, 1999a.

Lomans, B. P., Op den Camp, H. J. M., Pol, A., and Vogels, G. D.: Anaerobic versus aerobic degradation of dimethyl sulfide and methanethiol in anoxic freshwater sediments, Appl. Environ. Microbiol., 65, 438-443, 1999b.

Lomans, B. P., Smolders, A. J. P., Intven, L. M., Pol, A., Op den Camp, H. J. M., and van der Drift, C.: Formation of dimethyl sulfide and methanethiol in anoxic freshwater sediments, Appl. Environ. Microbiol., 63, 4741-4747, 1997.

Lomans, B. P., van der Drift, C., Pol, A., and Op den Camp, H. J. M.: Microbial cycling of volatile organic sulfur compounds, Cell Mol. Life Sci., 59, 575-588, 2002.

Miller, J. N. and Miller, J. C.: Statistics and Chemometrics for Analytical Chemistry, Pearson Education, Harlow, 2005.

Moran, J. J., Beal, E. J., Vrentas, J. M., Orphan, V. J., Freeman, K. H., and House, C. H.: Methyl sulfides as intermediates in the anaerobic oxidation of methane, Environ. Microbiol., 10, 162173, 2007.

Moran, J. J., House, C. H., Vrentas, J. M., and Freeman, K. H.: Methyl sulfide production by a novel carbon monoxide metabolism in Methanosarcina acetivorans, Appl. Environ. Microbiol., 74, 540-542, 2008.

Nüsslein, B. and Conrad, R.: Methane production in eutrophic Lake Plußsee: seasonal change, temperature effect and metabolic processes in the profundal sediment, Arch. Hydrobiol., 149, 597623, 2000.

Oelgeschläger, E. and Rother, M.: Carbon monoxide-dependent energy metabolism in anaerobic bacteria and archaea, Arch. Microbiol., 190, 257-269, 2008.

Przyjazny, A., Janicki, W., Chrzanowski, W., and Staszewski, R.: Headspace gas chromatographic determination of distribution coefficients of selected organosulphur compounds and their dependence on some parameters, J. Chromatogr., 280, 249-260, 1983. 
Reeves, E. and Seewald, J. S.: Methanethiol: A geochemical link between carbon and sulfur in hydrothermal systems? Geochim. Cosmochim. Acta, 73(Suppl.), A1079, doi:10.1016/j.gca.2009.05.014, 2009.

Scholten, J. C. M., Murrell, J. C., and Kelly, D. P.: Growth of sulfate-reducing bacteria and methanogenic archaea with methylated sulfur compounds: A commentary on the thermodynamic aspects, Arch. Microbiol., 179, 135-144, 2003.

Stets, E. G., Hines, M. E. and Kiene, R. P.: Thiol methylation potential an anoxic, low-pH wetland sediments and its relationship with dimethylsulfide production and organic carbon cycling, FEMS Microbiol. Ecol., 47, 1-11, 2004.

Tanimoto, Y. and Bak, F.: Anaerobic degradation of methylmercaptan and dimethyl sulfide by newly isolated thermophilic sulfatereducing bacteria, Appl. Environ. Microbiol., 60, 2450-2455, 1994.

Tallant, T.C., Paul, L., and Krzycki, J. A.: The MtsA subunit of the methylthiol:coenzyme M methyltransferase of Methanosarcina barkeri catalyses both half-reactions of corrinoid-dependent dimethylsulfide: coenzyme M methyl transfer, J. Biol. Chem., 276, 4486-4493, 2001. van Leerdam, R. C., de Bok, F. A. M., Lomans, B. P., Stams, A. J. M., Lens, P. N. L., and Janssen, A. J. H.: Volatile organic sulfur compounds in anaerobic sludge and sediments: Biodegradation and toxicity, Environ. Toxicol. Chem., 25, 3101-3109, 2006.

Visscher, P. T. and Taylor, B. F.: Aerobic and anaerobic degradation of a range of alkyl sulfides by denitrifying marine bacterium, Appl. Environ. Microbiol., 59, 4083-4089, 1993.

Weilacher, T., Gleixner, G., and Schmidt, H. -L.: Carbon isotope pattern in purine alkaloids. A key to isotope discriminations in C1 compounds, Phytochemistry, 41, 1073-1077, 1996.

Whiticar, M. J.: Carbon and hydrogen isotope systematics of bacterial formation and oxidation of methane, Chem. Geol., 161, 291-314, 1999. 